\title{
Open-Innovation in the Electrical and Electronic Industries: Engineered Bio-Fluid Compositions Are Paving the Way, and Testing Therewith
}

\author{
Serge Rebouillat ${ }^{1 *}$, Bernard Noirhomme ${ }^{2}$ \\ ${ }^{1}$ Currently with DuPont Int. Op., European Headquarters, Geneva, Switzerland \\ ${ }^{2}$ Institut de Recherche d'Hydro-Québec, Varennes, Canada \\ Email: serge.rebouillat@dupont.com
}

How to cite this paper: Rebouillat, S. and Noirhomme, B. (2018) Open-Innovation in the Electrical and Electronic Industries: Engineered Bio-Fluid Compositions Are Paving the Way, and Testing Therewith. Journal of Biomaterials and Nanobiotechnology, 9, 189-209.

https://doi.org/10.4236/jbnb.2018.92011

Received: March 8, 2018

Accepted: April 24, 2018

Published: April 27, 2018

Copyright $\odot 2018$ by authors and Scientific Research Publishing Inc. This work is licensed under the Creative Commons Attribution International License (CC BY 4.0).

http://creativecommons.org/licenses/by/4.0/

\begin{abstract}
Engineered Biofluids are paving the way to industrialized and specifically produced and tailored functional fluids such as coolant and dielectric, high purity traceable media, for the electrical and electronic industries. Dielectric fluid compositions are commonly used in electrical devices, particularly in transformers. These liquids have the aim to isolate the various conductive elements of the device and to limit the heating of the equipment during its operation; in order to minimize, or maintain at higher power, the size of the device and to increase the lifespan of it. Concomitantly a number of bio and traditional processing advancements are made associated with pioneering process technologies which are outlined within the prime context of this paper. Enzyme Engineering and Cocktailing add "A New Dimension to Softer Greener Chem-Bio Approaches" which are referenced beyond curiosity purpose. Some of them are possibly "revolutionary" more than evolutionary. Testing has to evolve accordingly to appreciate the challenges ahead in semi-extreme conditions which are relevant to climate changes as well. A significant part of this orientation work addresses and exemplifies these necessary testing innovations, likely adaptable to smart and responsive connecting, and further down the line bigger data role and learning machine evolutionary concepts. One other innovative part of this exploratory work, is the influence that such illustrative localized testing, with integrated sensors/induced-tracers, and on-line interpretation, may have on the smart grid developments; whereby production, transmission, distribution and consumption of energy can be made more reliable, more effective and more predictive and can also have an impact on the performance, reliability and sustainability of the equipment it-
\end{abstract}


self. Those technologies and associated testing can support environmental, technological and societal awareness; helping to revert some trends being climate changes, fossil fuel preservation and other planetary challenges to maintain the overall and localized fundamental equilibriums.

\section{Keywords}

Open Innovation, Green Technology, Electrical Behavior, Transformers, Extreme Conditions, Biofluids, Engineered Biofluids, Enzymes, Esterification

\section{Prime Introductive Objectives}

The use of biomaterials for industrial applications has increased significantly. Carbon footprints rationalization and food vs. fuel dilemma have been debated and made considerable progress towards a wider acceptance at various levels.

Open innovation contributes meaningfully with regards to: 1) softer, milder temperature biochemical processing which includes preconditioning, reactions, purification, zero waste, 2) raw materials and grain/seed selection of "just-as-needed" quality to start with, 3) fallow land exploitation rationalization, 4) usable agri-waste, 5) traceable land use, 6) water consumption minoration vs. agronomical food-related practice, 7) partial detachment from international seasonal trading [1] of agricultural commodities...

A practical principal object of this exploratory research work is to help alleviate some paradigms regarding new engineered biofluids as to their practical evidenced suitability to medium-extreme conditions.

An additional objective is to demonstrate that simulating side by side semi-extreme conditions and cold start-up operation not only can be done, but can uniquely be demonstrated and might be a premiere to even more stringent testing involving engineered biofluids, this within a smart on-line interactive operation prospective. Liquid filled electrical devices serve here has a relevant example.

Other objects will naturally derive from different elements appearing throughout the body of the study.

Keeping in mind that this study is intended as exploratory, indicative and of educational value mainly, and, does not replace the need for users to make their own compatibility tests using their own equipment and materials; still seeking appropriate professional support as per their best judgment.

\section{Preliminaries and Circumstantiated Background}

Alternative energies [2], Figure 1, as well as traditional electrical supplies and energy usage patterns are promoting innovation in the field of electricity production, its transmission, its transformation and its distribution.

Dielectric fluids compositions are commonly used in electrical devices, particularly in transformers. These liquids have the aim to isolate the various conductive 

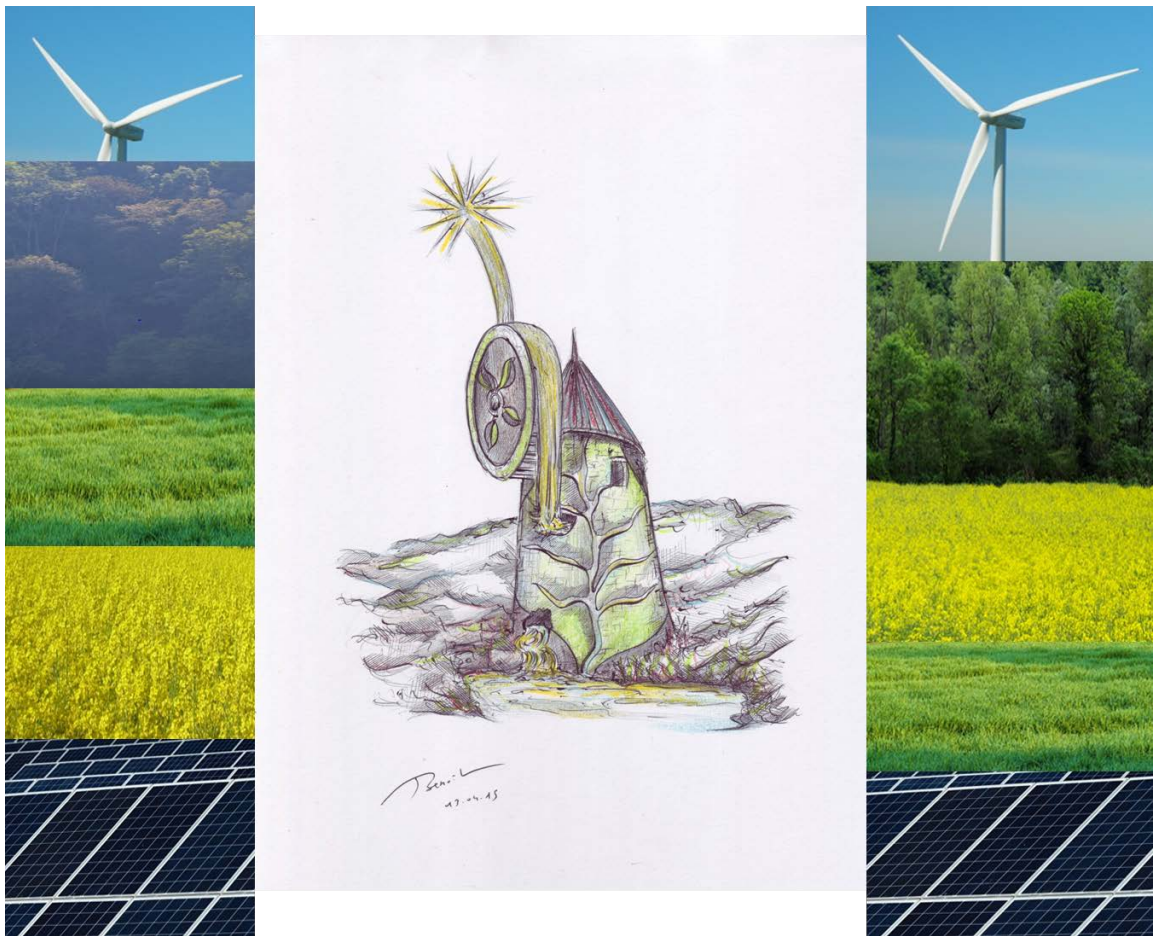

Figure 1. Alternative Energy Illustration designed with author's private art: wind turbines and photovoltaic solar factories among rapeseed fields with forests in the background and centrally, "inspirationally redesigned" old wind mill.

elements of the device and to limit the heating of the device during its operation, in order to minimize, or maintain at higher power, the size of the device and to increase the useful lifetime of it.

Much of the currently known dielectric liquid compositions are compositions comprising essentially hydrocarbons from specific cuts of crude oils. These compositions based on petroleum derivatives generally have a low ignition temperature (and therefore a significant flammability) and are also most often characterized by low biodegradability, if not a relative toxicity.

These liquids are now found to be relatively unsatisfactory for insulation of electrical devices. Indeed, especially when used in electrical transformers when large amounts of heat may be generated, these fluids present significant flammable risks. In addition, in case of breakage of the envelope of the electrical device, liquid-based petroleum derivatives are likely to cause significant pollution (soil, rivers, ground water...).

Therefore, to replace the dielectric fluids containing petroleum derivatives, one has sought to use compounds with interesting dielectric performances, which are nontoxic and biodegradable, and the synthesis of which is the cheapest possible. In this context, one has proposed including natural plant oils or animal waste fats as potential candidates, since some of them present some interesting insulation properties.

However, it has been found that natural plant oils cannot be used, in a certain number of cases, as such as dielectric fluids in electrical devices, for example, 
transformers. Indeed, they have certain disadvantages, including high viscosity (especially at low temperatures) associated with a high pour point, and in general, they also may exhibit an important tendency to oxidation pending on their source, refining or handling in general.

To improve the characteristics of vegetable oils it has been proposed to modify these oils, by adding antioxidants, antifreeze, or viscosity improvers. However, these additives are also generally non-biodegradable or toxic, they also sometime prove to be damaging to electrical devices in which they are used.

Attempts have been made to change the triglycerides (esters of glycerol and fatty acids) present in natural vegetable oils, in order to modify the properties of such vegetable oils without losing their biodegradability. In this regard, various attempts have been made to convert these esters of glycerol in esters of other alcohols.

This can be qualified as engineering of biofluids, such as WO 2004/108871 [3] which discloses liquid compositions that are based on modified oleic canola oil, or other matters with functionally equivalent fatty acid profiles, and are used as insulating liquids and heat transfer liquids, and electrical devices containing said liquid compositions. In this art, the liquid composition is based on a mixture of natural triglycerides and fatty acid esters of a branched alcohol for instance, said fatty acids usually derived from a vegetable oil, the mixture may optionally contain other esters.

Figure 2 is the molecular representation of one of the trans esterified components of the above patent [3].

In the recent research work, a fair amount of attention has been given to estolides as having potential for purposes that can bear suitability to above applications. An estolide is a unique oligomeric fatty acid that contains secondary ester linkages on the alkyl backbone of the molecule. This is also an engineered biofluid.

Estolides have typically been synthesized by the homopolymerization of castor oil fatty acids (Modak et al., JAOCS 42:428 (1965)). Castor oil (Ricinus communis), a "catamaran-like, flexible, symmetrical and balanced, molecular edifice", Figure 2, is a suitable dielectric for capacitors. Air conditioner capacitor, castor oil capacitor cbb65, are available commercially from Ghorit ${ }^{\mathrm{TM}}$ under that reference. Castor oil, unrefined, may have toxic attributes.

The terminal non linear feature of the above esters brings several benefits that are outlined by the proposed "new" testing. Its monounsaturation enhances the oxidation stability of the formulation when compared to the non trans esterified oils containing di and tri unsaturated entities such as linoleic acid and linolenic acid and esters thereof [3].

Indeed, transesterification, co-transesterification, inter-esterification are means to achieve such hybridized compositions and resulting engineered biofluids.

Esters of fatty acid composition subject to bio-engineering are generally based on esters of fatty acids of vegetable origin, plants in general, or wood treatment 

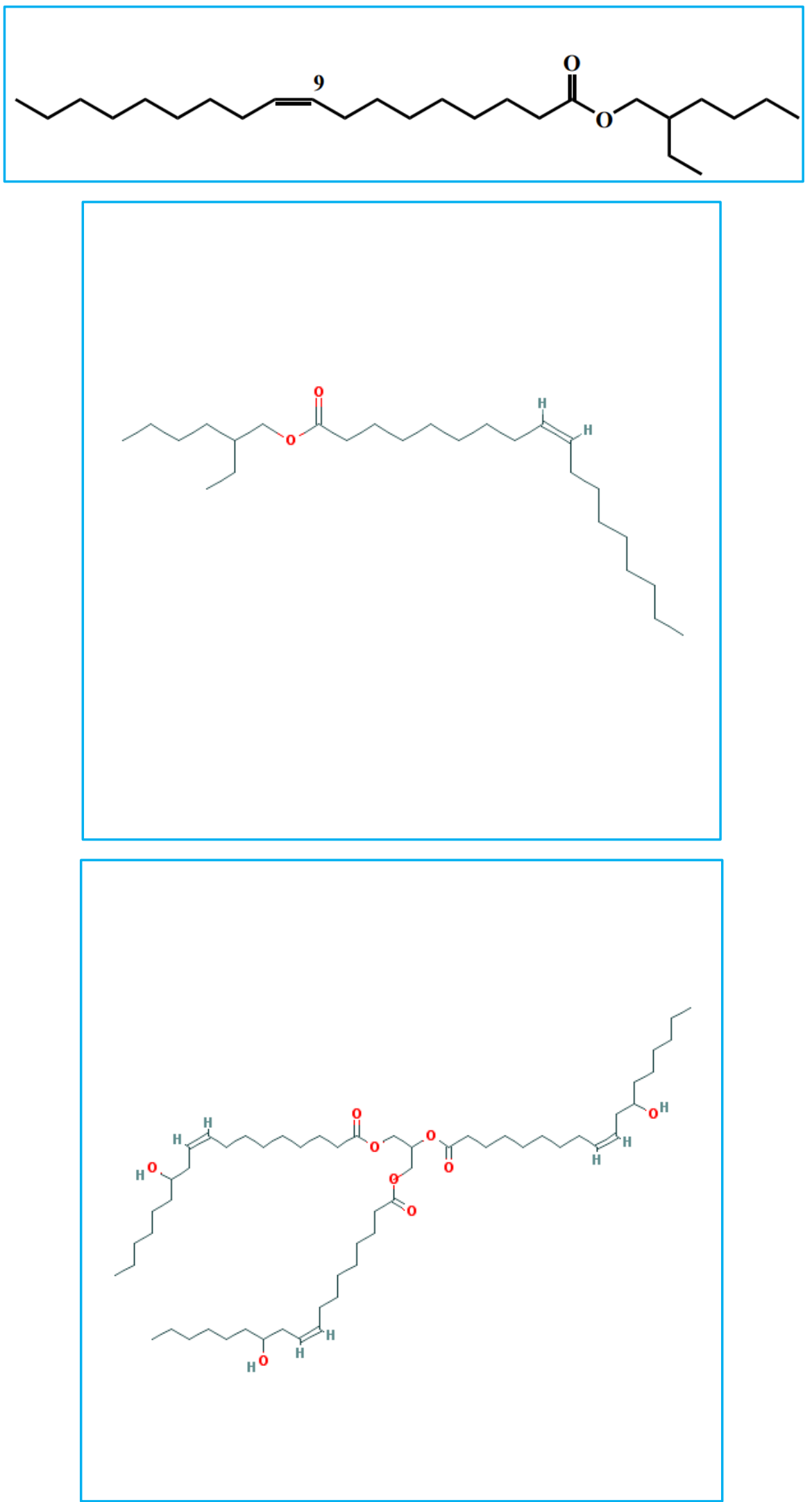

Figure 2. Oleic acid ester from vegetable oil bio-engineering [3], (the 2st molecular representations on top), and "castor oil" (3rd, framed at the bottom). 
derivates, such as tall oil, or algae or microalgae or animal fat or derived from sugars and sophorolipids. These fatty acids are usually derived from one or more of these raw materials.

Furthermore, the preservation of the integrity and properties of the oil and ester components, which have a beneficial, or at least a non-detrimental effect, on retention properties, such as oxidation resistance, is achieved via particularly well-tailored low temperature, short reaction time innovative processes.

Particular sensitive chemical families are for example the tocopherols and the sterols, naturally occurring in the selected components of the ingredients used to make the dielectric formulations. Those are natural antioxidants, which anti-antioxidation activity is very specific with regards to the composition of their various molecular families and their grouping.

Processing innovation are indeed evolving with softer biochemical approaches such as per Rebouillat et al.'s patent WO2013052956, which process concept is schematically represented below on Figure 3. Such softer processes look at carrying out the manufacturing of dielectric formulations directly from the seeds/grains. Such initiative also partly materialized in the field of biofuels as per WO2009/013349 patent application. Additionally, protecting the materials during processing such as during grease manufacturing is illustrated in WO2010/ 124118 patent application, using micro-waves technology for example.

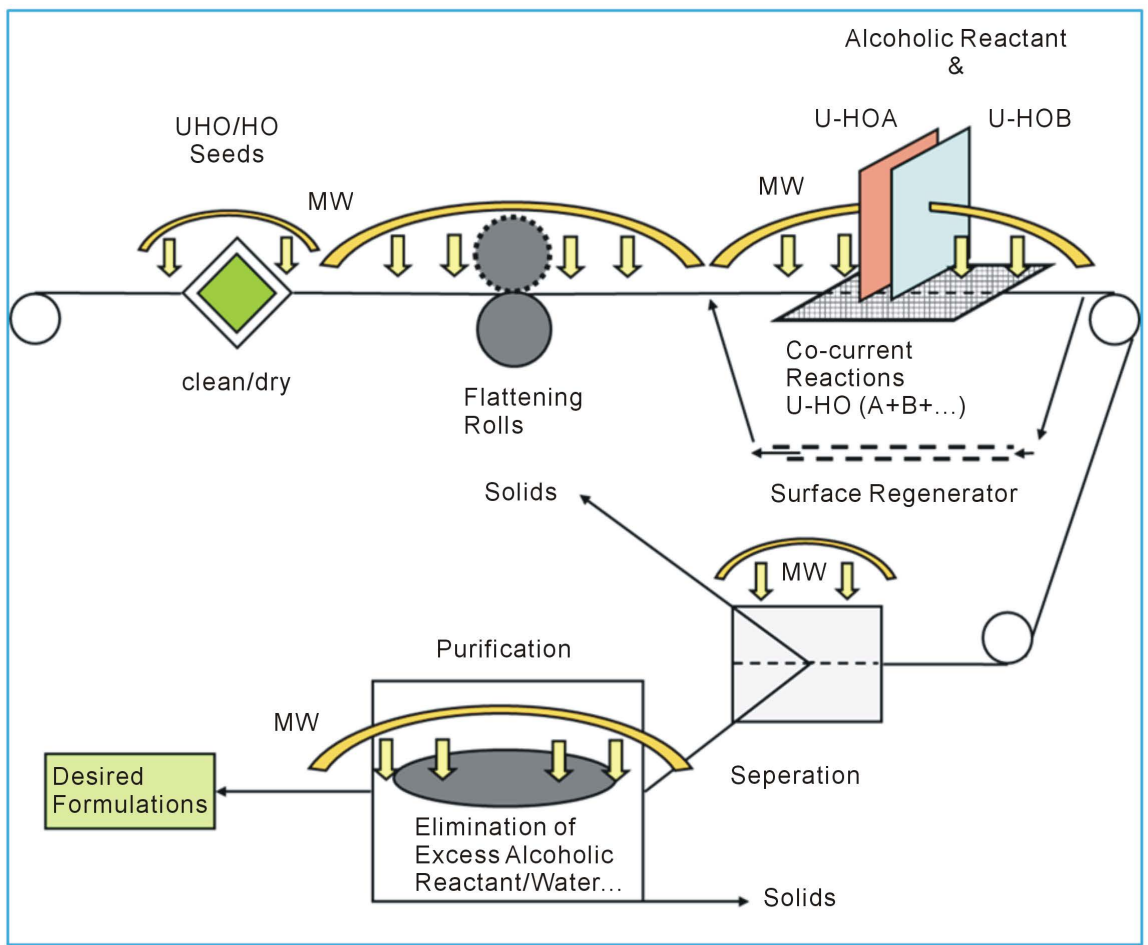

Figure 3. From Seeds to Desired Dielectric Formulations (PCT/US2012/059259-Serge Rebouillat): an innovation prospect consolidating advantages of enzyme catalyzed continuous co-transesterification (ECCE), microwave (MW) exposure and other softer conditions for instance low temperature, biochemical processing of advanced ultra-high-oleic (UHO) and high oleic oils (HO) from new breeds. 
A particular advantage of the micro-waves, MW, is that they heat the product from within and at a lower temperature such that the product qualities are maintained, even after heating. The dielectric formulation of interest in this work appeared especially suitable to optimize that effect, thus leading to a higher yield in a shorter time laps.

As general guidance and Table 1 below, reactions, in the preferred media, occurring in hours take place in less than minutes with an improved yield, and a 10x reduction of non-productive side reactions.

Both referenced processes of WO2009/013349 and WO2010/124118 have been invented to produce significantly different products, respectively biofuels and greases [4], which specifications are far apart from the requirements of the desired formulations of dielectric fluids capable of heat absorption.

New and softer chemical and biochemical processes and unit operations are worth keeping in mind, i.e.:

- Millifluidic and microfluidic processing.

- Super Critical $\mathrm{CO}_{2}-\mathrm{SC} \mathrm{CO}_{2}$

- Water and alternative solvents extractions

- Centrifugal Molecular Distillation

- Reverse Osmosis

- Molecular Diffusion Processing

- Molecular Separation

- Cryogenic Fractioning

- Dry-Solvent Free-Fractioning

- Ultra-high Vacuum Distillation

- Enzyme Engineering and Cocktailing for On-time specific Catalysis [4] [5]

- Nanoporous Membrane Separation

- Ultra, Micro, Nano Filtration

- With "Bigger Data and Learning Machine" Process Approaches

Overall [2] [3], "Vegetable Oil Liquid Dielectric Transformers" and "Application of Vegetable Oil-Based Fluids as Transformer Oil" provide suitable, historical

Table 1. From WO2010/124118 patent application.

\begin{tabular}{ccc}
\hline 90 Sec Microwave* Exposure & Temperature & Temperature after \\
\hline Sample & at start $\left({ }^{\circ} \mathrm{C}\right)$ & $90 \mathrm{Sec}\left({ }^{\circ} \mathrm{C}\right)$ \\
HOBO ${ }^{* *}$ & 22 & 109 \\
Mineral Oil & 23 & 39 \\
$5 / 95 \mathrm{HOBO} /$ Mineral Oil & 23 & 44 \\
10/90 HOBO/Mineral Oil & 24 & 51 \\
25/75 HOBO/Mineral Oil & 24 & 60 \\
$50 / 50 \mathrm{HOBO} /$ Mineral Oil & 23 & 75 \\
$75 / 25 \mathrm{HOBO} /$ Mineral Oil & 23 & 96 \\
\hline
\end{tabular}

${ }^{\star} 1.75 \mathrm{KW}$ microwave input; ${ }^{* *} \mathrm{HOBO}=$ High Oleic Bean Oil. 
and contemporaneous, basics and backgrounds to understand the type of materials involved in the experimental part of this work; and to figure out adjacency with the above contextual trends and happenings.

\section{Further Incentive}

The Figure 4 below was somehow the preliminary study's key finding [6] that made the following exploratory work a captivating challenge that HQ-IREQ institution chose to take from \& with the principal author's suggestion, leadership and organizational support. All data and experimental features remain under the control of HQ-IREQ which declines all responsibility for "use" and interpretation.

It is interesting to note that among evaluated esters, Engineered Biofluid B exhibits the lowest viscosity values. This condition is necessary to achieve a high transfer capacity. Therefore, worth the cold static and dynamic tests.

In the following, we present the results of our studies [6] comparing the thermal performance of two different oils, a standard commercial mineral oil and an oil prototype B supplied by DuPont ${ }^{\mathrm{TM}} /$ Valagro. Beside the laboratory evaluation, the thermal properties of the oil type B in a transformer was evaluated.

These tests were conducted with distribution transformer under a protocol further described below.

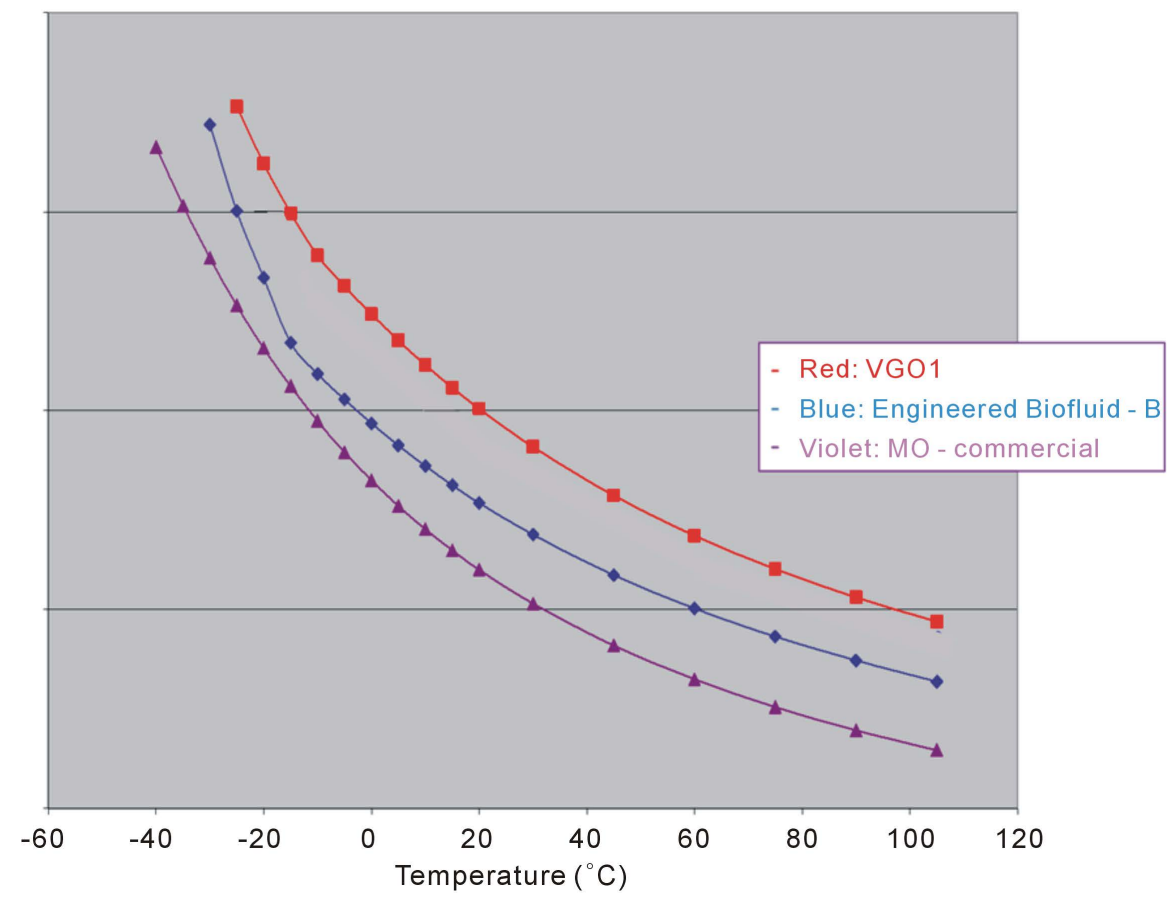

Figure 4. Downward thermally-induced variation of kinematic viscosity [6] between $40^{\circ} \mathrm{C}$ and $100^{\circ} \mathrm{C}$ for 2 ester types of oils [7], i.e. one $100 \%$ HO soybean purified oil sample, VGO1, and one Engineered Biofluid, B, and one commercial mineral oil, MO, as per more generic description in [2] [3] (measurements made according to ASTM D7042 test method using an Anton Paar SVM 3000 instrument which give results equivalent to ISO 3104 and ASTM D445 methods). 
Due to the availability of two instrumented distribution transformers, it was decided to concentrate our efforts on the study of the oil thermal behavior in these distribution transformers.

The overall objective is to compare the thermal behaviour of a distribution transformer filled with prototype B against a commercial reference mineral oil at room temperature and at a fairly low temperature $\left(-20^{\circ} \mathrm{C}\right)$.

In a similar context, back in 2015 [8], B. Cloet et al., at CG Power Systems Belgium and OWI-lab, conclude their "Cold start of a 5.5MVA offshore transformer" study with the following proposal for future work:

- "Measurement of the winding temperature with several optical fibers installed inside the windings."

The present study just preceded the above and conclusive remark.

Their proposal is further justified by the patent work of S. Rebouillat, WO2010111698, on transformer insulation paper, impregnated with biofluid compositions, exposed to microwave/electromagnetic fields; whereby oil and impregnated cellulose paper are subject to these favorable field exposures.

LV (Low Voltage) and HV (High Voltage) windings and oil localized thermal measurements may help characterizing those effects.

\section{Materials and Experimental Protocols [6]}

\subsection{Testing Environment}

Climate chambers are standardized. Suitable testing environments and climate chambers are available at Hydro-Quebec's IREQ research centre where the work was performed. As outlined by this Institution: "Environmental testing facilities meet industry standards and include climate chambers where various types of equipment can be performance-tested under a wide range of conditions". (http://www.hydroquebec.com/innovation/en/testing-calibration-repair-services html).

The climate chamber is $2.5 \mathrm{~m} \times 2.5 \mathrm{~m} \times 6 \mathrm{~m}$. RH at RT is about $30 \%$ to $40 \%$.

Multipurpose pubic installation is also available at

(http://www.owi-lab.be/content/climate-chamber-testing). For education purpose, such a typical large multipurpose climatic test chamber, includes:

- Dimensions: $11 \mathrm{~m} \times 7 \mathrm{~m} \times 8 \mathrm{~m}$

- Capability to test $>150$ ton machinery

- Temperature range: $-60^{\circ} \mathrm{C}$ to $+60^{\circ} \mathrm{C}$

- Thermal cycling possibilities

- Thermal camera to monitor test campaign in extreme temperatures

- $2 \% \mathrm{RH}$ to $95 \% \mathrm{RH}$

- Solar Infrared-heat $10-1000 \mathrm{~W} / \mathrm{m}^{2} / 3 \mathrm{~m} \times 3 \mathrm{~m}$ array

- Large cooling capacity: $+60^{\circ} \mathrm{C}$ to $-40^{\circ} \mathrm{C}$ air temp in 1 hour

- Icing \& ice-spray tests possible

- Cold start-test-up bench for gearboxes available ( $10 \mathrm{kNM}$ break-away torque)

- Flexible power set-up $50 \mathrm{~Hz} / 60 \mathrm{~Hz}$ up to $10 \mathrm{MW}$ for electrical testing load 
testing

\subsection{Electrical Devices}

Two instrumented distribution transformers are comparably suitable for test, one $100 \mathrm{kVA}$ and one $167 \mathrm{kVA}$ (see Tables 2-4 for technical details). Only the $100 \mathrm{kVA}$ has been used for the heat run test at room temperature and at low temperature. The $167 \mathrm{kVA}$ transformer specifications are described below for information only and referencing.

The transformer has been energized at $1 \mathrm{PU}$ by applying a current on the low voltage side while the high voltage side is short-circuited.

The current will be applied at 25\%, 50\%, 75\% and $100 \%$ of the nominal value until the thermal stability is attained for each value.

Table 2. Two Typical Suitable Pieces of Equipment-Right, grayed zone, transformer which has been used.

\begin{tabular}{|c|c|c|c|}
\hline Equipment & & \multicolumn{2}{|c|}{ Two distribution transformers } \\
\hline & Type: & \multicolumn{2}{|c|}{$\begin{array}{l}\text { Pole transformer, ONAN, “Oil Natural Air Natural” (unforced), } \\
\qquad 60 \mathrm{~Hz}, 65^{\circ} \mathrm{C} \text { rise }\end{array}$} \\
\hline & \multirow{6}{*}{$\begin{array}{l}\text { Nominal } \\
\text { value }\end{array}$} & $\mathrm{PU}=167 \mathrm{kVA}$ & $\mathrm{PU}=100 \mathrm{kVA}$ \\
\hline & & $\mathrm{E}_{\mathrm{L}}=24940 \mathrm{VY} / 14400 / 240 / 120 \mathrm{~V}$ & $\mathrm{E}_{\mathrm{L}}=24940 \mathrm{VY} / 14400 / 240 / 120 \mathrm{~V}$ \\
\hline & & $\mathrm{I}_{\mathrm{HV}}=11.5 \mathrm{~A}$ & $\mathrm{I}_{\mathrm{HV}}=6.9 \mathrm{~A}$ \\
\hline & & $\mathrm{I}_{\mathrm{LV}}(240 \mathrm{~V})=695.8 \mathrm{~A}$ & $\mathrm{I}_{\mathrm{LV}}(240 \mathrm{~V})=416.7 \mathrm{~A}$ \\
\hline & & Impedance @85 $\mathrm{C}=1.9 \%$ & Impedance @85º = 2.3\% \\
\hline & & Impedance LV @85 ${ }^{\circ} \mathrm{C}=6.55 \mathrm{~m} \Omega$ & 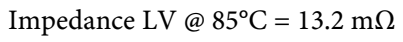 \\
\hline & Capacity/ & Oil volume: $170 \mathrm{~L}$ & Oil volume: $145 \mathrm{~L}$ \\
\hline & Weight & Weight: 660 kg (1452 lbs) & Weight: 475 kg (1045 lbs) \\
\hline
\end{tabular}

Table 3. Maximum voltage and current obtained at 2.2 PU (max. of the current source).

\begin{tabular}{ccc}
\hline & $167 \mathrm{kVA}$ & $100 \mathrm{kVA}$ \\
& maximum current and voltage at $2.2 \mathrm{pu}$ \\
Low voltage side & $1531 \mathrm{~A}, 10 \mathrm{~V}$ & $916.7 \mathrm{~A}, 12.1 \mathrm{~V}$ \\
High voltage side & $25.5 \mathrm{~A}, 601.8 \mathrm{~V}$ & $15.3 \mathrm{~A}, 728.7 \mathrm{~V}$ \\
\hline
\end{tabular}

Table 4. Physical characteristics of the $100 \mathrm{kVA}$ transformer used.

\begin{tabular}{cc}
\hline Core weight (kg) & 186.3 \\
HV weight & 49.3 \\
LV weight & 27.0 \\
Oil quantity (L) & 145 \\
Tank and accessories weight & 49.4 \\
Winding height (mm) & 257 \\
HV nb. layer & 14 \\
LV nb. layer & 12 per winding \\
Oil duct in HV layer & $1,4,6,8,10$ and 13 \\
Oil duct in LV & 6 (external and internal)
\end{tabular}




\subsection{Fluids}

Two oils were used for the test:

- a reference mineral naphthenic based oil 10CX, a commercial oil from NYNAS $^{\mathrm{sm}}$. A type II oil inhibited with DBPC as antioxidant (https://www.nynas.com/en/).

- an oil supplied by DuPont ${ }^{\mathrm{Tm}} /$ Valagro, (DuPont International Operations, CH1218, Switzerland), as oil "B", an early prototypical Engineered Biofluid made via transesterification of a high oleic Brassica family oil with a branched alcohol. Fluid B may now be represented by the commercial fluid, Nomex ${ }^{\circledast} 970$ FLD.

References [2] [3] provide sufficient details to apprehend these types of fluid more precisely. Electric and dielectric properties are provided in these references as well.

\subsection{Instrumented Electrical Devices}

Heat run tests are performed with high voltage terminal in short-circuit as shown in Figure 5 for the selected $100 \mathrm{kVA}$ equipment.

A total of 30 thermocouples monitored the temperatures variations during the heat cycles at different locations of the transformer (oil, windings, ambiant). The exact thermocouple locations are detailed in Table 5 and Figure 6. Such a density of instrumentation warrants reliability and preventive detection of deficiencies.

Thermocouples have been installed axially in the low tension winding internal (LV int.), high tension windings (HV), low tension windings external (LV ext.) and in the oil, top and bottom of the transformer. Another thermocouple has been installed outside the transformer within $1 \mathrm{~m}$ distance to measure the room temperature, RT.

Thermocouples are used to measure the temperature within the windings and in the oil of the transformers. T type thermocouples were used. The thermocouples have been soldered on thin copper plate of $1 \mathrm{~cm}^{2}$. They have been installed during the transformer manufacturing under supervision of IREQ experts

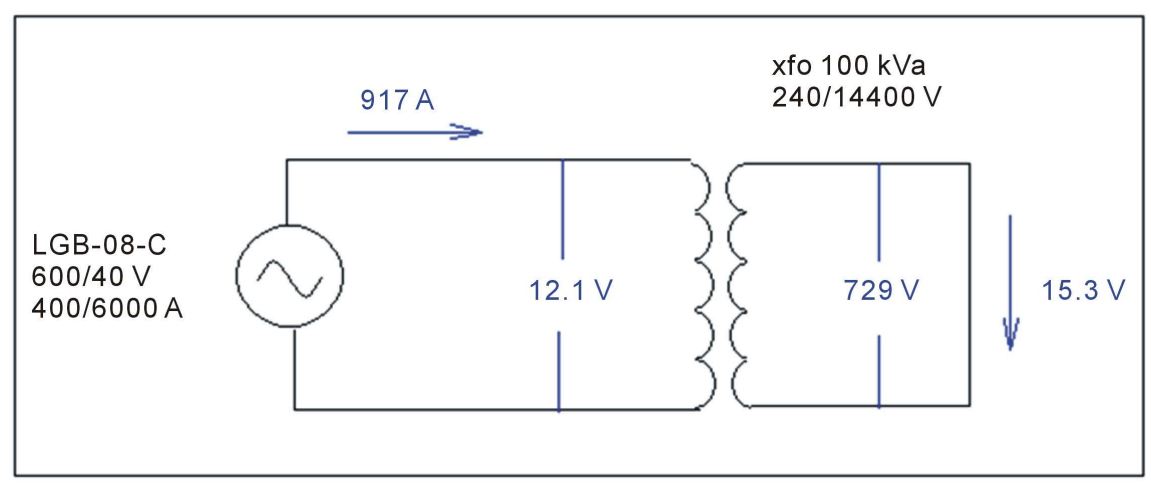

Figure 5. Electrical diagram including maximum voltage and current for $100 \mathrm{kVA}$ xfo (Transformer). 
Table 5. Detailed locations of thermocouples within the transformer windings and in the oil and ambient.

\begin{tabular}{|c|c|c|c|}
\hline Component & $\mathrm{nb}$ & \# & Location of thermocouples \\
\hline \multirow[t]{6}{*}{$\begin{array}{l}\text { LV_int } \\
\text { (X2X3) }\end{array}$} & 9 & $1,2,3,4,5,6,7,8,9$ & At the 6th layer: LV internal \\
\hline & & & $1,2,3,4,5$ \\
\hline & & & At the 3rd layer: LV internal \\
\hline & & & 6,7 \\
\hline & & & At the 9th layer \\
\hline & & & 8,9 \\
\hline \multirow[t]{6}{*}{$\begin{array}{l}\text { LV_ext } \\
(\mathrm{X} 1 \mathrm{X} 2)\end{array}$} & 9 & $10,11,12,13,14,15,16,17,18$ & At the 6th layer: LV external \\
\hline & & & $10,11,12,13,14$ \\
\hline & & & At the 3rd layer: LV external \\
\hline & & & 15,16 \\
\hline & & & At the 9th layer \\
\hline & & & 17,18 \\
\hline \multirow[t]{9}{*}{$\mathrm{HV}(\mathrm{H} 1 \mathrm{H} 2)$} & 9 & $19,20,21,22,23,24,25,26,27$ & At the 3rd layer \\
\hline & & & $19,20,21$ \\
\hline & & & At the 7 th layer \\
\hline & & & $22,23,24$ \\
\hline & & & At the 12 th layer \\
\hline & & & $25,26,27$ \\
\hline & 3 & Tc high & $\begin{array}{l}\text { Top oil } 2 \mathrm{~cm} \text { below the oil surface at } \\
\text { center of the tank }\end{array}$ \\
\hline & & Tc low & $\begin{array}{l}\text { Bottom oil } 2 \mathrm{~cm} \text { above the bottom tank } \\
\text { halfway between tank and winding }\end{array}$ \\
\hline & & Tc ambiant & Room temperature \\
\hline
\end{tabular}

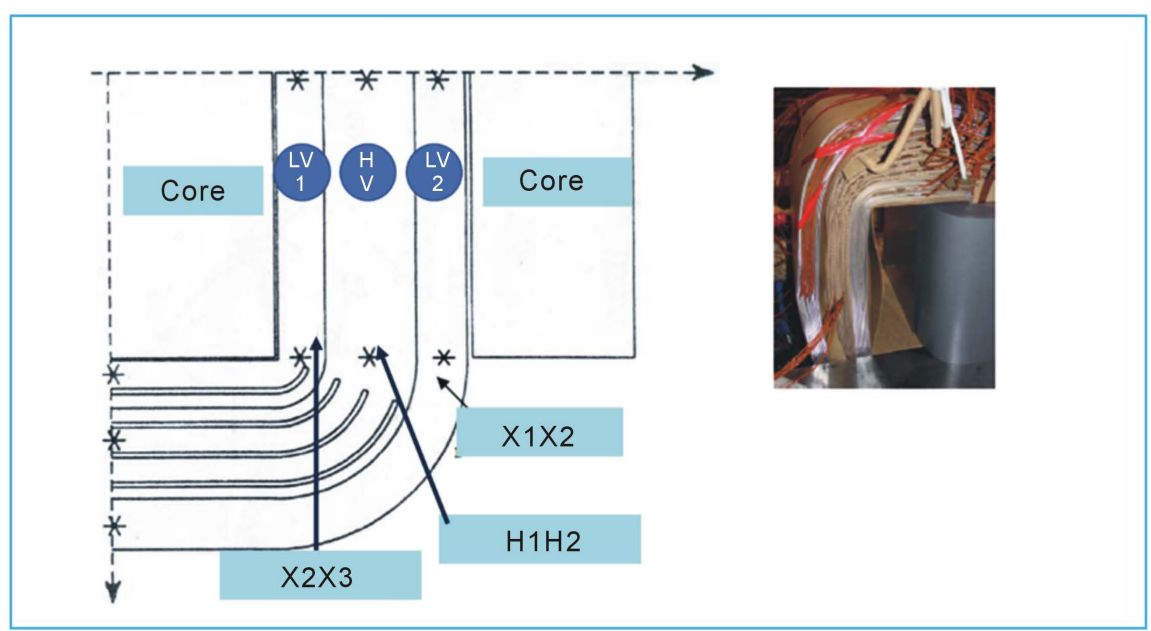

Figure 6. Installation of thermocouples within the coil-core assembly. 
(and checked Temperature are recorded every 30 sec. Precision of temperature measurement are within $+/-2^{\circ} \mathrm{C}$.

\subsection{Oil and Transformer Conditioning}

At each oil change, the oil and the transformer were degassed in a vacuum chamber. First the oil was drain and removed from the transformer, and it was put under vacuum in a vacuum chamber for at least $48 \mathrm{H}$ at a vacuum level lower than $0.01 \mathrm{mmHg}$. The new degassed oil was introduced under vacuum in the transformer. The transformer was then kept under vacuum for another $24 \mathrm{H}$ to remove all the trapped air.

These operations assure that the oil is kept dry, but cannot avoid the cross contamination. When the mineral oil was drained from the transformer and replaced by the Engineered Biofluid B, there was still a small amount of mineral oil mixed with B. It is generally admitted that between two fillings, $2 \%$ to $5 \%$ of the total oil volume is left in the winding.

Oil samples were taken before and after heat run. A syringe and bottle were sampled and analyzed at the IREQ laboratory at the different steps of the measurements. The lab oil analysis reports and results are discussed later.

\section{Base Equation for Calculations [6]}

The winding temperature measurement is calculated from winding resistance measurement according to the procedure described in IEEE C57.12.90-2010. The formula used for temperature calculation, knowing the winding resistance follows:

$$
\mathrm{Rs}=\mathrm{Rm}(\mathrm{Ts}+\mathrm{Tk}) /(\mathrm{Tm}+\mathrm{Tk})
$$

where:

Rs is the resistance at desired temperature Ts $(\Omega)$

$\mathrm{Rm}$ is the measured resistance $(\Omega)$

Ts is the desired reference temperature $\left({ }^{\circ} \mathrm{C}\right)$

Tm is the temperature at which resistance was measured $\left({ }^{\circ} \mathrm{C}\right)$

$\mathrm{Tk}$ is $234.5^{\circ} \mathrm{C}$ (copper) or $225^{\circ} \mathrm{C}$ (aluminum)

An average temperature of each winding was obtained by winding resistance measurement. During the winding resistance measurement, the power is shut off and the temperature decreases slowly. To evaluate the decrease in temperature of each winding, we use the average temperature winding deduced from the average temperature of all the thermocouples located in each winding. The average temperature difference is added to the temperature obtained from the winding resistance measurement.

\section{Results and Discussion [6]}

The set-up reliability and the repeatability and reproducibility of the experimental protocol are long established given the maintenance consistency and use of, 
the climate chamber and the electrical equipment. Regarding the current work any inconsistency detection and "reproducibility and repeatability" aspects are secured by the running of 2 different temperature campaigns, 30 sensor live recording at 6 different positions (windings, oil and RT). The recordings and machine graphs instead of re-computerized figures help to visualize and attest to this.

\subsection{Steady State Approach at Thermal Steadiness}

The following, top and bottom parts of Table 6 compare the temperature rises calculated from winding resistance measurements at the different steps of the experiment from 0.25 to $1 \mathrm{PU}$ for the commercial Nynas ${ }^{\mathrm{Tw}} 10 \mathrm{CX}$ and the Engineered Biofluid $\mathrm{B}$ at $\mathrm{RT}$ and at $-20^{\circ} \mathrm{C}$. The bottom and top oil temperatures are also listed for comparison.

Table 6. Winding average temperature, temperature rise and oil temperature measured during heat cycles with $\mathrm{Nynas}^{\mathrm{TM}} 10 \mathrm{CX}$ (top table) and the Engineered Biofluid B (bottom table).

\begin{tabular}{|c|c|c|c|c|c|c|c|c|c|}
\hline Temp & Load PU & $\mathrm{X} 3 \mathrm{X} 2$ & Rise & $\mathrm{X} 1 \mathrm{X} 2$ & Rise & $\mathrm{H} 1 \mathrm{H} 2$ & Rise & Oil temp Bottom & Top \\
\hline & & Average & & Average & & Average & & & \\
\hline & & Temp & & Temp & & Temp & & & \\
\hline \multirow[t]{5}{*}{$\mathrm{RT}$} & 1 & 85.6 & 59.6 & 85.6 & 59.6 & 89.2 & 63.2 & 53.9 & 79.8 \\
\hline & 0.25 & 30.7 & 5.3 & 30.4 & 5 & 31.9 & 6.5 & 27.6 & 30.1 \\
\hline & 0.5 & 44.2 & 18.1 & 43.5 & 17.4 & 45.8 & 19.7 & 33.6 & 42 \\
\hline & 0.75 & 62.9 & 35.1 & 62.3 & 34.5 & 65.2 & 37.4 & 43.2 & 59 \\
\hline & 1 & 94.3 & 61.5 & 92.2 & 59.4 & 94.2 & 61.4 & 58 & 85 \\
\hline \multirow[t]{7}{*}{-20} & 0.25 & -10.8 & 10 & -13.2 & 7.6 & -12.7 & 8.1 & -18.8 & -16.4 \\
\hline & 0.5 & 3.1 & 23.9 & -1.4 & 19.4 & 3 & 23.7 & -14.2 & -5.9 \\
\hline & 0.75 & 20.3 & 40.9 & 16.3 & 36.8 & 20.6 & 41.2 & -6.8 & 11.1 \\
\hline & 1 & 41.4 & 61.7 & 38.2 & 58.5 & 42 & 62.3 & 4 & 32 \\
\hline & Load PU & $\mathrm{X} 3 \mathrm{X} 2$ & Rise & $\mathrm{X} 1 \mathrm{X} 2$ & Rise & $\mathrm{H} 1 \mathrm{H} 2$ & Rise & Oil Temp Bottom & Top \\
\hline & & Average & & Average & & Average & & & \\
\hline & & Temp & & Temp & & Temp & & & \\
\hline \multirow[t]{5}{*}{ RT } & 1 & 87.4 & 63.1 & 86.2 & 61.9 & 89.5 & 65.2 & 58.3 & 78 \\
\hline & 0.25 & 33.3 & 9.4 & 31.7 & 7.8 & 32.8 & 8.9 & 26.9 & 28.8 \\
\hline & 0.5 & 46.5 & 21.8 & 45.3 & 20.6 & 47 & 22.3 & 33.7 & 40.6 \\
\hline & 0.75 & 65.1 & 39.6 & 63.6 & 38.1 & 66.6 & 41.1 & 44.7 & 58 \\
\hline & 1 & 89.7 & 64.3 & 88.4 & 63 & 91.3 & 65.9 & 57.4 & 80 \\
\hline \multirow[t]{4}{*}{-20} & 0.25 & -4.1 & 15.9 & -6.6 & 13.4 & -4.9 & 15.1 & -15.2 & -17.2 \\
\hline & 0.5 & 7.3 & 27.5 & 2.7 & 22.9 & 7.8 & 28 & -12.2 & -3.6 \\
\hline & 0.75 & 25.4 & 45.1 & 21.3 & 41 & 26.7 & 46.4 & -2.6 & 13.8 \\
\hline & 1 & 48.5 & 67.1 & 45.2 & 63.8 & 50.4 & 69 & 10.6 & 37.4 \\
\hline
\end{tabular}


It is noted that the calculated average temperature has been compared to the measured average temperature obtained from the thermocouples installed at the different location of the windings. Fairly good agreement was obtained in most of the cases.

It is observed in all cases that the temperature rise of $\mathrm{H} 1 \mathrm{H} 2$ (HV Winding) is higher than X1X2 and X2X3 LV windings likely due to its location between the two LV windings.

At RT, the temperature rise with mineral oil and the rise with the biofluid $B$ are very comparable. The rise difference is a little bit more pronounced with the heat run test made at low temperature $-20^{\circ} \mathrm{C}$.

Oil samples have been taken at different steps of the experiments. The following variations have been observed for mineral oil and for oil type B after heat run:

- For mineral oil, the easiest observable variation is the content of water that increases significantly after the $1 \mathrm{PU}$ thermal cycle. This is expected if we consider the migration of water from the paper to the oil when the winding temperature increases. Accordingly, the dielectric breakdown decreases when the water content increases. No noticeable variation of oil physical parameters. Very small variation of gas content is also observed.

- For the Engineered Biofluid B the oil physical tests are in accordance to what is expected for an oil of this type: higher power factor and acidity and lower interfacial tension. An increase of water content in the oil is also observed after thermal cycle, however the dielectric breakdown voltage does not decrease. This seems to support the hypothesis that the dielectric breakdown is more sensitive to relative moisture saturation rather than to the absolute water content in the oil.

Those are hypothesis to be further supported.

On-line tracing opportunity may derive from such observations.

\subsection{Dynamic Approach}

In essence, dynamic orientation approaches are highly valuable for testing, on-line monitoring and operation optimization.

Figure 7 shows an illustration of the variation of temperature measured by the thermocouples in the $\mathrm{X} 2 \mathrm{X} 3$, windings; this was conducted at all three positions X2X3, X1X2 and $\mathrm{H} 1 \mathrm{H} 2$; trends were similar. The top of the Figure 7 shows the temperature variation obtained with the commercial Nynas ${ }^{\mathrm{TM}} 10 \mathrm{CX}$ and on the bottom the variation obtained with the biofluid $B$. In addition to the thermocouples located in the windings, the ambient (red), the bottom (green) and the top temperatures (blue) have been added on each graph. The transformer has been submitted to a step from 0 to $0.25 \mathrm{PU}$ at $-20^{\circ} \mathrm{C}$.

By comparison of the thermal behavior at $-20^{\circ} \mathrm{C}$ of the Nynas ${ }^{\mathrm{TM}} 10 \mathrm{CX}$ and the Engineered Biofluid B the following observations can be made:

- In the thermal cycle at $0.25 \mathrm{PU}$ with oil type B the top oil temperature is low- 
er than the bottom oil temperature (green and blue line) possibly due to the fact that the convection regime is not yet installed due to the higher oil viscosity.

- We have noted that in the next step 0.25 to $0.50 \mathrm{PU}$ an inversion occurs and at the end when the $0.5 \mathrm{PU}$ is reached the top oil temperature is higher than the bottom oil temperature.

The following Figure 8 shows the variation of temperature within the LV winding at the same position $\mathrm{X} 2 \mathrm{X} 3$, (the other $\mathrm{LV}$ winding and the $\mathrm{HV}$ winding showed similar responses) during a 0 - 1 PU step heat run at $-20^{\circ} \mathrm{C}$ with the transformer filled with biofluid B (Bottom) in comparison with the reference mineral oil (Top).

It is observed that the transformer filled with the Engineered Biofluid B behaved differently for an initial short period of time. A rapid initial increase of the temperature winding followed by a plateau is observed while the top oil temperature is low and constant for a certain time and increase only after a while. A possible explanation is that the top oil temperature is low and constant until the decrease of the oil viscosity, due to the temperature increase, which lower viscosity

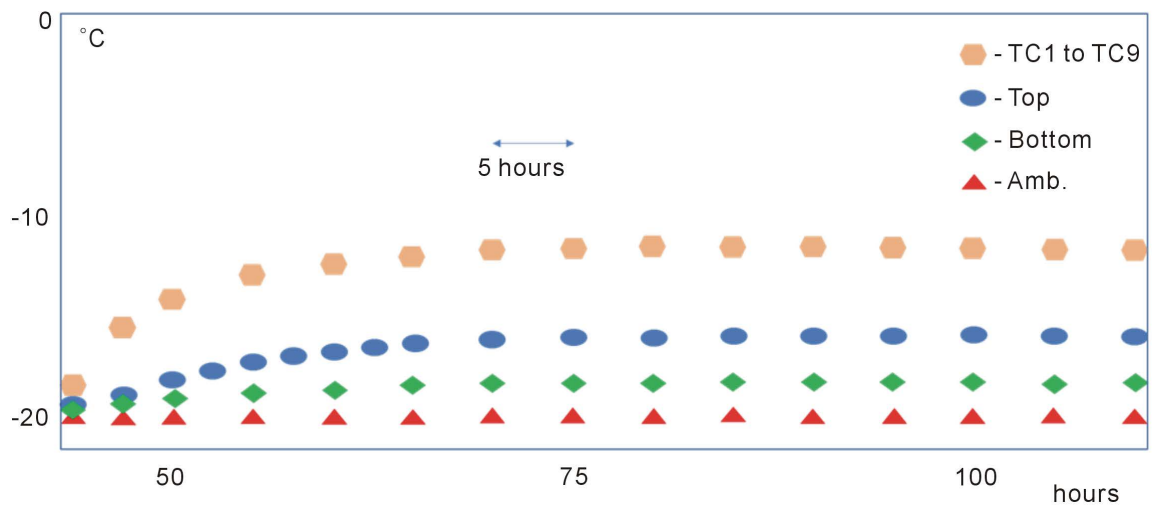

(a)

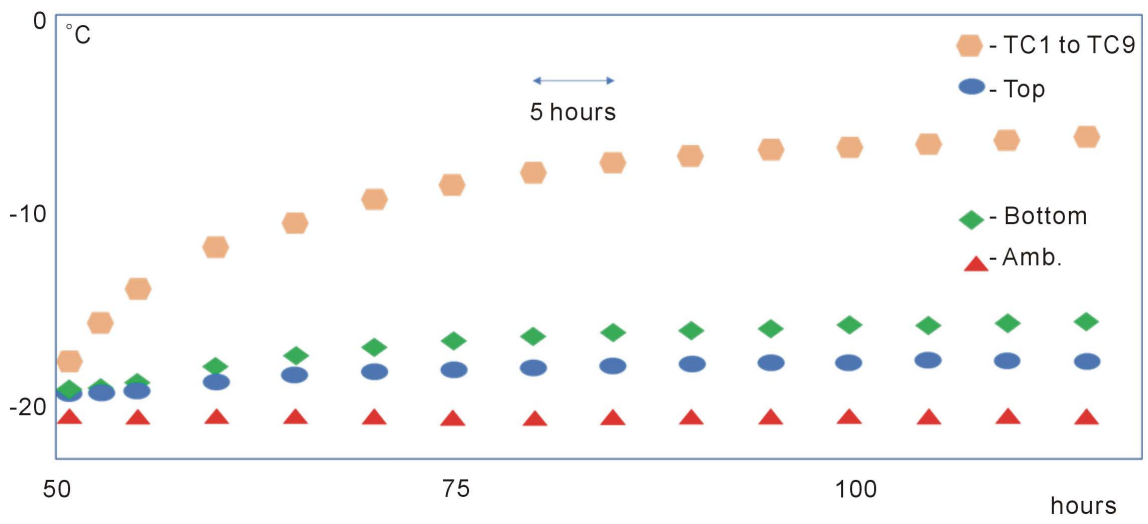

(b)

Figure 7. LV winding $\mathrm{X} 2 \mathrm{X} 3$ submitted to a $0-0.25 \mathrm{PU}$ heat run at $-20^{\circ} \mathrm{C}$ (top: $\mathrm{Nynas}^{\mathrm{Tm}}$ 10CX, bottom: Engineered Biofluid B, the ambient (red), the bottom (green) and the top temperatures (blue)). (a) Reference Mineral Oil recording, time in hours; (b) Engineered Biofluid B recording, time in hours. 


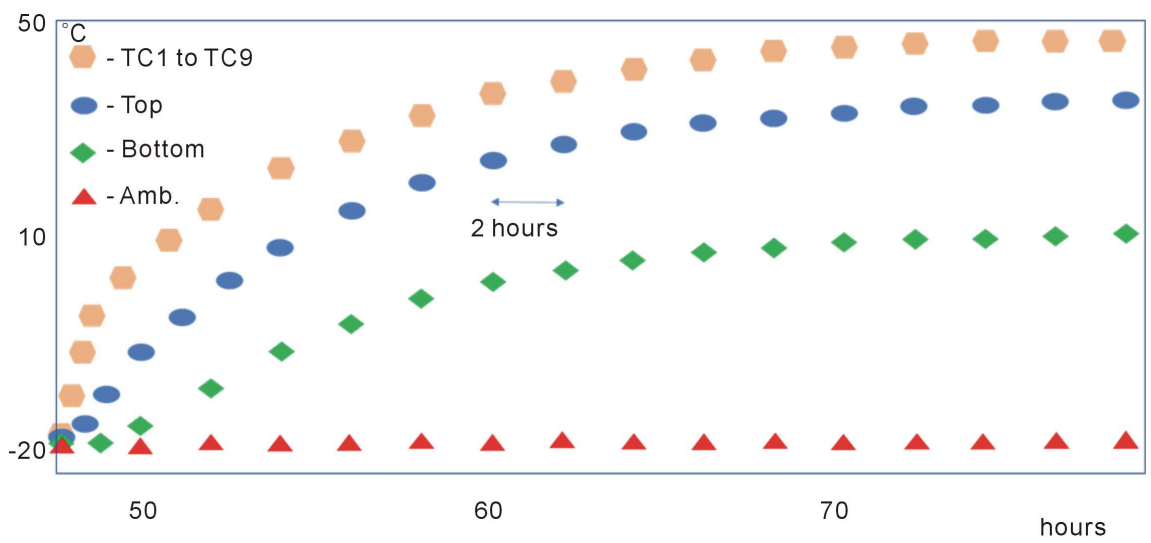

(a)

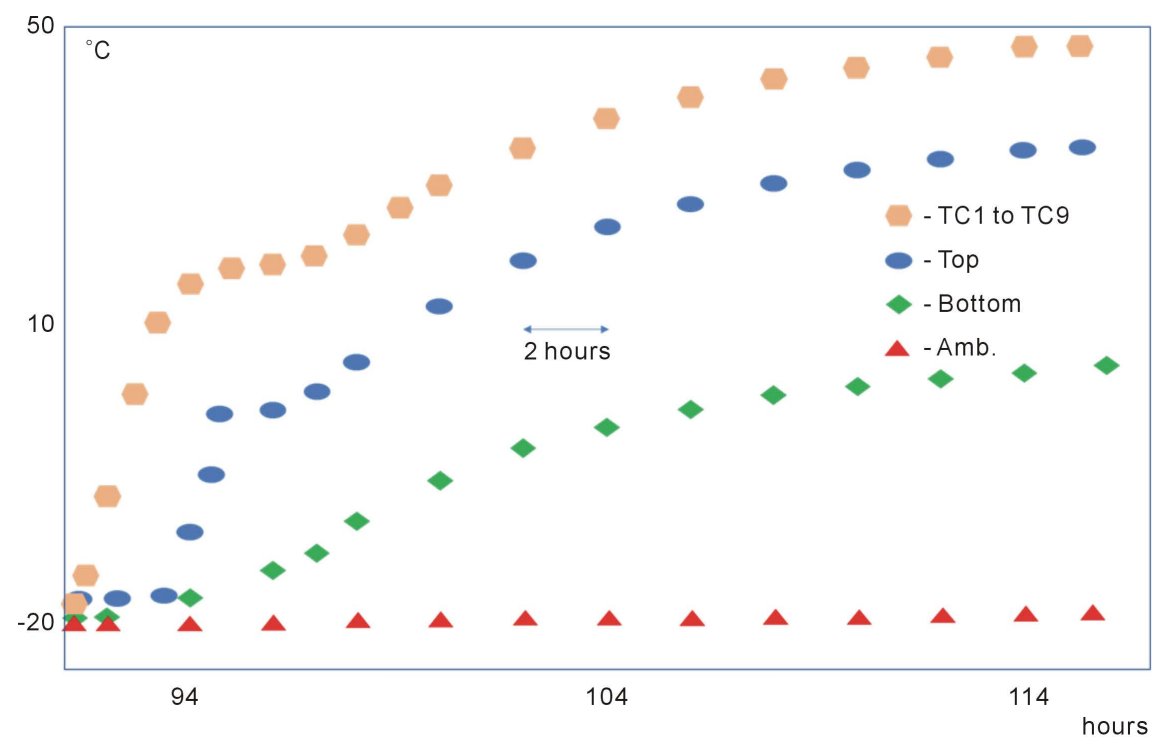

(b)

Figure 8. $\mathrm{LV}$ winding $\mathrm{X} 2 \mathrm{X} 3$ submitted to a $0-1 \mathrm{PU}$ heat run at $-20^{\circ} \mathrm{C}$ (top: reference mineral oil Nynas ${ }^{\mathrm{Tm}} 10 \mathrm{CX}$, bottom: Engineered Biofluid B, the ambient (red), the bottom (green) and the top temperatures (blue)). (a) Reference Mineral Oil recording, time in hours; (b) Engineered Biofluid B recording, time in hours.

allows the oil convection to take place. After the oil convection takes place the rapid increase of the temperature winding becomes a lower increase.

This shows clearly that the thermal behavior of the biofluid $\mathrm{B}$ at $-20^{\circ} \mathrm{C}$ will allow a cold load pick-up at $1 \mathrm{PU}$ without any oil overheating. For even lower temperatures this has still to be verified, and is certainly worthwhile a test exploration given this main unique demonstrative result and the relevant finding conclusions; the rheology of the biofluid as exhibited on Figure 4 remains a driver for that endeavor.

\section{Conclusions, Path Forward and General Trends}

Engineered Biofluids are paving the way to industrially and specifically produced and tailored functional fluids; e.g. heat and dielectric, high purity traceable me- 
dia, for the electrical and electronic industries.

Along these lines, a number of processing, "evolutionary and conceivably revolutionary", advancements could be made associated with pioneering process technologies, for instance:

- Millifluidic and microfluidic processing-Super Critical $\mathrm{CO}_{2}$, i.e. SC $\mathrm{CO}_{2}$-Water and alternative Solvents extractions-Centrifugal Molecular Distillation-Reverse Osmosis-Molecular Diffusion Processing-Molecular Separation-Cryogenic Fractioning-Dry-Solvent-Free Fractioning_Ultra-high Vacuum Distillation-Enzyme Engineering and Cocktailing for On-time Catalysis-Nanoporous Membrane Separation-Ultra, Micro, Nano Filtration-On-line analytical monitoring, tracing and Smart operation.

And as well, advanced material formulations and blends, like biosourced-polymers, nanocellulose, carbon and aramids in various forms-pulps, micro and nano-pulps [9] [10] [11] [12]—which can enhance system performance with better energy and fossil fuel conservation and sustainability, lower weight-performance ratio, and greater durability.

Those technologies and associated testing can support environmental, technological and societal awareness; helping to revert some trends being climate changes, fossil fuel preservation and other planetary challenges to maintain the overall and localized fundamental equilibriums. In other words, a "balanced" "ecotropism" in the sense of preserving these overall and localized fundamental equilibriums and harmonious interactions thereof.

The immediacy and the pedagogical benefits of the above, should help to draw the forms and contours of the intellectual challenges ahead and should motivate future illustrative works that would remove paradigms and encourage entrepreneurial risk taking, agility and speed.

The exploratory and orientation, practical work, outlines the following learning and foreseeable approaches [6]:

The measurements performed on instrumented distribution transformers filled with a reference mineral oil and an Engineered Biofluid-B-show comparable temperature rise. Thermal behavior of $\mathrm{B}$ at $-20^{\circ} \mathrm{C}$ would allow the use of this oil at $-20^{\circ} \mathrm{C}$ at least for a $0-1 \mathrm{PU}$ cold load pick up without any problem of thermal runaway.

Let's mention for calibration purpose that the cold load pick-up at HQ-IREQ involves a 0 to $2.2 \mathrm{PU}$ for $4 \mathrm{H}$ (4 hours) followed by $1.8 \mathrm{PU}$ for $3 \mathrm{H}$ at $0^{\circ} \mathrm{C}$.

Additional work on instrumented transformers and/or new transformers with Engineered Biofluids needs to be further considered given these promising exploratory results derived from these rather unique illustrative sets of runs.

Such a "smart" adaptively driven experimentation could serve to the betterment of "smart" network/grid designs, their requirement definition and fine tuning. Development of learning machines to that effect, would advantageously replace the older generation of programmable modules; assuming at least the same or better risk management can be put in place. 
The following further practical work could be explored:

- Behavior at lower temperature $-30^{\circ} \mathrm{C},-40^{\circ} \mathrm{C}$.

- Test with different cold load pick up patterns and temperatures.

- Comparison of the Engineered Biofluid B and refined 100\% vegetable oils.

- Testing on different types of bio based oil sourcing.

And to end with a colorful illustration, let's reflect on the enzymatic engineering and cocktailing illustration in Figure 9, which adds a New Lock-an-Key Dimension to Softer Greener Chem-Bio Approaches.

\section{Acknowledgements}

The authors thank:

- Antoine Piccirilli: Valagro ${ }^{\mathrm{rm}} /$ Biosynthis $^{\mathrm{Tm}} /$ Olvea $^{\mathrm{Tm}}$, “Oléo" Scientist/World Sommite in the field. Gratefulness for elevated discussions on the "spirit" of oils and other not less important matters. A "friend above all".

- Benoit Steffenino: DuPont ${ }^{\mathrm{Tm}}$ Fellow technologist, a favorite "ex-student" that you never "abandon". His pictorial skills bring concepts to an entertaining journey.

- France Rochette: DuPont ${ }^{\mathrm{rm}}$, gate keeper in business relevance analysis with a distinguished and highly balanced technology/business collaborative mindset. Her people-approach magical fluency made a difference.

- Guillaume Bray: $\mathrm{ERDF}^{\mathrm{rm}} / \mathrm{Enedis}^{\mathrm{rm}}$, Directeur de Cabinet et Communication; diplomacy and enthusiasm, his nature, make a significant impact on implementation steps.

- Imre Horvath: DuPont ${ }^{\mathrm{Tx}} / \mathrm{Solvay}^{\mathrm{m} x}$, "most demanded" business strategist; his rationality and implementation talents are key drivers to meet such a milestone. A “jealously sought-after Master”.

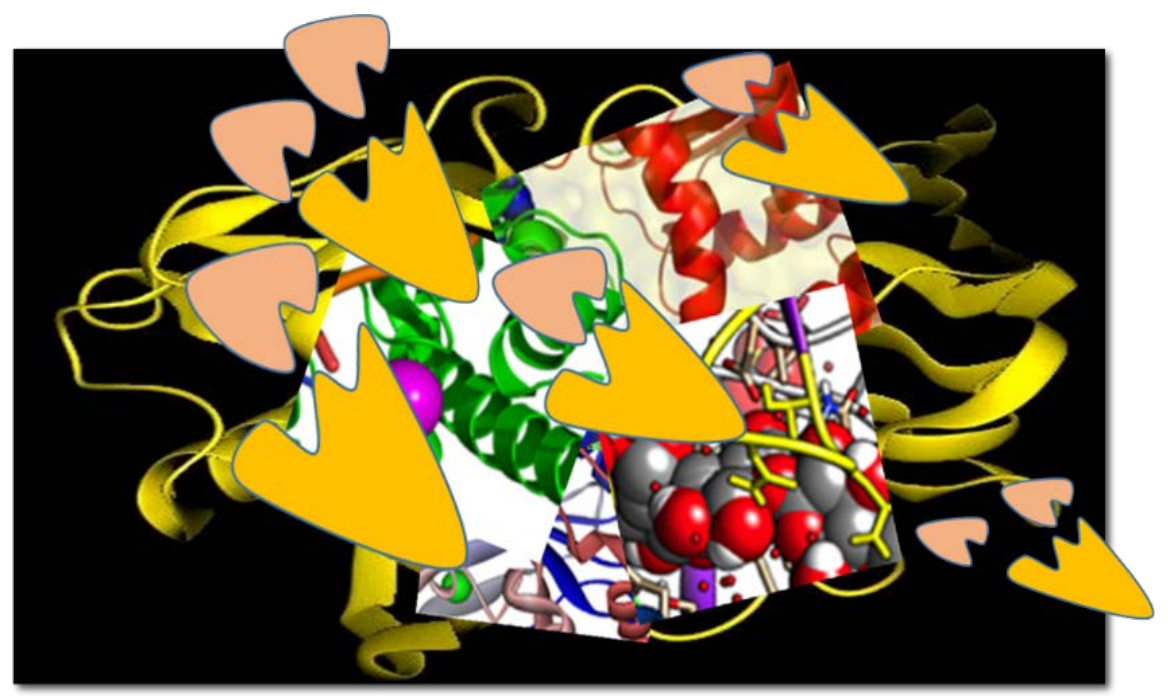

Figure 9. Enzyme Engineering and Cocktailing-A New Dimension to Softer Greener Chem-Bio Approaches. 
- Julien Magne: Valagro ${ }^{\mathrm{Tw}} /$ Biosynthis $^{\mathrm{Tw}}$, extraordinary skilled Chem-Biotech engineer, a pioneer of the integrated processing of oils from raw agri-materials.

- Louis Gastonguay, Jocelyn Jalbert, Marta Cea de Ruano: IREQTM/ Hydro-Québec ${ }^{\mathrm{TM}}$, a talented research and communication team, who made the full story an open innovation dreamed "épopée".

- Lou Honary: Iowa University ${ }^{\text {tw }}$, World Authority, VGO expert; gratitude for his early support in the field and WW openness.

- Michael E. Lyons: $\mathrm{TCD}^{\mathrm{m}}$, Dublin, for his ability to make electrochemistry an art and a science pertinent to industrial mindsets and innovation thereafter; "Paving the Way to the Integration of Smart Nanostructures I and II" [13] [14] generated with S. Rebouillat significant open and innovative exchanges.

\section{Disclaimer}

This article is primarily for educational purposes. Selected cases are strictly illustrative. Neither the authors nor the illustrator assumes any liability for any errors or oversights, for how this article or its contents are utilized or interpreted or for any consequences resulting directly or indirectly from the usage of it.

This information is for general knowledge. For critical applications, requirements should be checked with the suppliers. For additional guidance, legal or any other, seek advice from the appropriate qualified professionals; this study can by no means substitute for legal, technical and managerial expert advice.

The opinions expressed by the writers in this article do not necessarily represent the viewpoints of the companies the authors are employed by.

\section{References}

[1] Rebouillat, S. (2013) A Science and Business Equation for Collaborative Corporate Innovation. Business Strategy, IP Strategy, R \& D Strategy: An All-in-One Business Model. A Review with a Bio-Technology and Green Chemistry Focus. International Journal of Innovation and Applied Studies, 4, 1-19.

[2] http://www.groupe-cahors.com/sites/default/files/argu_transfos_huile_vegetale_eng .pdf

[3] http://www.abiosus.org/docs/5_Biermann_ApplicationOfVegetableOil-basedFluids AsTransformerOil.pdf

[4] Antczak, M.S., Kubiak, A., Antczak, T. and Bielecki, S. (2009) Enzymatic Biodiesel Synthesis-Key Factors Affecting Efficiency of the Process. Renewable Energy, 34, 1185-1194. https://doi.org/10.1016/j.renene.2008.11.013

[5] Passosa, C.P., Yilmaza, S., Silvaa, C.M. and Coimbrab, M.A. (2009) Enhancement of Grape Seed Oil Extraction using a Cell Wall Degrading Enzyme Cocktail. Food Chemistry, 115, 48-53.

[6] Noirhomme, B. and Rebouillat, S. (2014) Internal Report, "Evaluation of Oil... in Distribution Transformer".

[7] Balderas Lopez, J.A., Monsivais Alvarado, T., Galvez Coyt, G., Munoz Diosdado, A. and Diaz Reyes, J. (2013) Thermal Characterization of Vegetable Oils by Means of Photoacoustic Techniques. Revista Mexicana de Física, 59, 168-172.

[8] http://www.owi-lab.be/sites/default/files/Final_CG_paper\%20Cold\%20start\%20and 
\%20storage\%20test\%20on\%205\%205MVA\%20WTG\%20transformer.pdf

[9] Rebouillat, S. (2016) Aramids: "Disruptive", Open and Continuous Innovation. In: Chen, X., Ed., Advanced Fibrous Composite Materials for Ballistic Protection, Woodhead Publishing Limited, Cambridge, 11. https://doi.org/10.1016/B978-1-78242-461-1.00002-9

[10] Rebouillat, S. (1998) Carbon Fiber Applications in Carbon Fibers. 3rd Edition, CRC Press, New York, 573 p.

[11] Rebouillat, S. and Pla, F. (2016) Recent Strategies for the Development of Biosourced-Monomers, Oligomers and Polymer-Based Materials: A Review with an Innovation and a Bigger Data Focus. Journal of Biomaterials and Nanobiotechnology, 7, 167-213. https://doi.org/10.4236/jbnb.2016.74017

[12] Rebouillat, S. and Pla, F. (2013) State of the Art Manufacturing and Engineering of Nanocellulose: A Review of Available Data and Industrial Applications. Journal of Biomaterials and Nanobiotechnology, 4, 165-188. https://doi.org/10.4236/jbnb.2013.42022

[13] Lyons, M.E.G. and Rebouillat, S. (2009) Paving the Way to the Integration of Smart Nanostructures: Part 1 Paving the Way to the Integration of Smart Nanostructures: Part 1: Nanotethering and Nanowiring via Material Nanoengineering and Electrochemical. International Journal of Electrochemical Science, 4, 481-515. http://www.electrochemsci.org/papers/vol4/4040481.pdf

[14] Rebouillat, S., Lyons, M.E.G., Doyle, B.M.P. and Richard, L. (2011) Paving the Way to the Integration of Smart Nanostructures: Part II: Nanostructured Microdispersed Hydrated Metal Oxides for Electrochemical Energy Conversion and Storage Applications. International Journal of Electrochemical Science, 6, 5830-5917. 